\section{Progress with inventories}

SIR - When regretting the lack of an inventory of life (see Gaston and Mound Nature 361, 579; 1993), we should be careful to distinguish the complete list of organisms, that is including many as yet undiscovered species, from the smaller set of just those that have already been described. That we have no inventory of the former is inevitable (we have neither seen them all, nor estimated with certainty how many millions there are), whereas the more surprising omission is that there is no master inventory even of those species that have been dealt with by taxonomists.

Gaston and Mound offer sensible advice: concentrate our forces on selected groups. What they omit to mention is that substantial progress is now being made in doing exactly this, the production of master inventories for selected groups. Be it of bacteria ${ }^{1,2}$, protists $^{3}, \quad$ insects ${ }^{4}$, molluscs ${ }^{3}$, fish ${ }^{5}$, fungi ${ }^{6}$, plants $^{7,8}$ or plant fossils ${ }^{9}$, a series of global synonymized taxon checklists are making progress. These are databases carefully prepared by teams of specialists to be available soon on-line or distributed on disc. Producing master catalogues requires specialist software (for example, ALICE ${ }^{10}$, "Linnaeus"11, pcTROPICOS $^{12}$ ) and cooperative management to obtain a very wide range of taxonomic expertise. New levels of international organization have been needed in projects such as the ILDIS Leguminosae database ${ }^{7}$ to turn regional monographs into workable worldwide classifications and to select a preferred reference system where taxonomists debate alternative taxonomies.

The first public taxonomic databases have experimented with the handling of alternative taxonomies (as in the US Nature Conservancy's taxonomic inventory with local variants), with attaching biological data in such a way that it can be refreshed for subsequent taxonomic changes (for example, ILDIS/Chapman and Hall Leguminosae phytochemical database $^{13}$ ), and with the use of images (such as The Plant Fossil Record ${ }^{9}$ ). The adoption of standards by TDWG ${ }^{14}$ networking and the first steps towards 'taxonomically intelligent' integrity checking are enabling a second generation to appear. Gaston and Mound may have to wait before the 750,000 insects can be handled, but IOPI $^{15}$ is already building on the expertise of ILDIS $^{\gamma}$, TROPICOS ${ }^{16}$ and the Australian Plant Census $^{17}$ to create a system for the

Letters submitted for Correspondence should be typed, double-spaced, on one side of the paper only.

Frank A. Bisby world's 250,000 vascular plants. $\mathrm{ETI}^{3}$ is similarly working on protists, birds and molluscs.

If insects are being named at the rate of about 7,250 species a year and synonymized at about 1,450 a year, then these rates are within our capacity for entry into master inventories. Resources are, however, a major limiting factor. It remains something of a surprise that at a time when conserving species diversity is valued so highly, so little priority is given to listing the basics of what species there are to be conserved or lost. But substantial progress is being made and the most important resources of all, expertise and know-how, are now becoming available. Do not despair!

Biodiversity \& Bioinformatics

Research Group,

University of Southampton,

Southampton SO9 3TU, UK

1. DSM. List of Valid Bacterial Names (Deutsche Sammlung von Mikroorganismen and Zellkulturen, Braunschweig).

2. BIOSIS TRF. BIOSIS Bacterial Taxonomic Reference File (BIOSIS, Philadelphia).

3. ETI. Linnaeus Protist (also Mollusc and Bird systems) (Expert-Center for Taxonomic Identification. Amsterdam).

4. ANI. Arthropod Name Index. (CAB International, Wallingford).

5. Eschmeyer, W.N. Taxonomic Database for Fishes (California Academy of Sciences, San Francisco).

6. IMI. Species Fungorum Database (International Mycology Institute, Egham).

7. ILDIS International Legume Database \& Information Service (iLDIS Phase 1, Version 1.8) (ILDIS Coordinating Centre, Southampton).

8. CITES. CITES Cactaceae Checklist (Royal Botanic Gardens, Kew)

9. IOPB. The Plant Fossil Record Database Version 1.0 (International Organisation of Palaeo-Botany, London)

10. ALICE. Species Diversity Data Management System (ALICE Software Partnership, Kew)

11. Linnaeus. Multi-Media Taxonomic Information System (ETI-Center, Amsterdam).

12. pC-TROPICOS. Comprehensive Database Management System for Systematic Botany. (Missouri Botanical Garden, St Louis)

13. ILDIS/Chapman \& Hall. Legume Phytochemical Database (ILDIS Phase 2, Phytochem. Module, Version 0.7). (ILDIS Co-ordinating Centre, Southampton).

14. TDWG. International Working Group on Taxonomic Databases for Plant Sciences (a commission of the International Union of Biological Sciences).

15. IOPI. International Organization for Plant Information.

16. TROPICOS. The Botanical Database of the Missouri Botanical Garden (Missouri Botanical Garden, St Louis).

17. Hnatiuk, R.J. Census of Australian Vascular Plants (Bureau of Flora \& Fauna, Canberra, 1990).

SIR - Gaston and Mound consider that "for the foreseeable future, description of all the world's species will remain impossible". They are right. It is impossible to describe all the species that currently inhabit the planet given, for example, that species evolve and that there would be no obvious way of knowing when the table was complete.

The more practical challenge that faces the taxonomic community is to describe and classify all the species that are known to inhabit the world. This task is not impossible, just very difficult.
The productivity and size of the work force involved and the rate at which undescribed species become known are clearly important factors.

The Instituto Nacional de Biodiversidad (INBio) in Costa Rica has shown that, together, parataxonomists and taxonomists can make astonishing progress towards an inventory of species. INBio provides a model that other tropical countries are already starting to follow.

Information technology lies at the heart of almost all current projects and international initiatives such as the International Organisation for Plant Information (IOPI) are converging on common approaches. The taxonomic literature and major catalogues of species are clear targets for conversion to machine readable form and technologies for automating this process are increasingly being used.

Gaston and Mound are right that in taxonomy, as in science in general, the drive comes from individuals. But the community comprising these individuals is responding to the biodiversity crisis by setting priorities and defining focused research programmes. In the major taxonomic institutions, the emphasis is firmly on collaboration and concerted action, as initiatives such as the recently formed European Museums Network emphasize.

New ways of working will take taxonomy into the fast lane, providing information on species, the components of biodiversity. This is essential if the scientific quality of studies of biodiversity at the ecosystem and genetic level is not to be compromised.

\section{Stephen Blackmore}

Natural History Museum,

London SW7 5BD, UK

SIR - I believe that if a current inventory of known insect and other species was available, descriptive work might be more efficient than the current 20 per cent wastage rate (due to synonymy).

But we are faced with a cultural problem where descriptive work goes unrewarded, and systematics and taxonomy are often treated as one. With encouragement, a competent amateur can diagnose species and varieties without resot to parsimony analysis.

Also, the extinction of a species is not the end of the story: insect taxonomy simply transfers to archaeoentomology with attendant information loss.

Systematists need not only to communicate with nature conservationists but also to appraise them. Otherwise, Nero will play at the computer while forests burn, and sentiment rather than science will decide the issue.

\section{E. A. Jarzembowski}

Brighton Borough Council,

Town Hall, Brighton BN1 1 A, UK 